\title{
A Public Survey on Handling Male Chicks in the Dutch Egg Sector
}

\author{
B. Gremmen ${ }^{1,2}$ - M. R. N. Bruijnis ${ }^{1} \cdot$ V. Blok $^{2}$ - E. N. Stassen ${ }^{1}$
}

Accepted: 2 January 2018/Published online: 16 January 2018

(C) The Author(s) 2018. This article is an open access publication

\begin{abstract}
In 2035 global egg demand will have risen 50\% from 1985. Because we are not able to tell in the egg whether it will become a male or female chick, billons of one day-old male chicks will be killed. International research initiatives are underway in this area, and governments encourage the development of an alternative with the goal of eliminating the culling of day-old male chicks. The Netherlands holds an exceptional position in the European egg trade, but is also the only country in the European Union where the downside of the egg sector, the practice of killing day-old male chicks, is a recurrent subject of societal debate. 'Preventing the killing of young animals' and 'in ovo sex determination' are the two alternative approaches available to solve this problem. It is clear that both approaches solve the problem of killing day-old male chicks, either by keeping them alive or by preventing them from living, but they also raise a lot of new animal welfare-related dilemmas. A thorough analysis was undertaken of these dilemmas and the results are presented in this article. The analysis resulted in an ethical framework based on the two main approaches in bioethics: a consequentialist approach and a deontological approach. This ethical framework was used to develop an online survey administered to ascertain Dutch public opinion about these alternative approaches. The results show that neither alternative will be fully accepted, or accepted by more than half of Dutch society. However, the survey does provide an insight into the motives that are important for people's choice: food safety and a good treatment of animals. Irrespective of the approach chosen, these values should be safeguarded and communicated clearly.
\end{abstract}

B. Gremmen

bart.gremmen@wur.nl

1 Adaptation Physiology Group, Animal Sciences Group, Wageningen University, P.O. Box 338, $6700 \mathrm{AH}$ Wageningen, The Netherlands

2 Philosophy Group, Wageningen University, P.O. Box 8130, 6700 EW Wageningen, The Netherlands 
Keywords Animal ethics · Animal welfare $\cdot$ Chicks $\cdot$ Laying hens $\cdot$ Public opinion

\section{Introduction}

In 2035 global egg demand will have risen 50\% from 1985 (Mulder 2017). Because we are not able to tell in the egg whether it will become a male or female chick, billons of one day-old male chicks will be killed. Only in the last few years consumers are informed about this practice and they are appalled (Leenstra et al. 2011). International research initiatives are underway in this area, and the governments of Australia, Germany, the Unites States of America and the United Kingdom encourage the development of alternatives with the goal of eliminating the killing of day-old male chicks (Reporter link 2017). Will their consumers prefer these alternatives to the current situation? The Dutch situation could give valuable insights because the Netherlands holds an exceptional position in the European egg trade. With a contribution of $41.4 \%$ to the EU shell egg exports and a share of $12 \%$ of global export volume in 2013 (Windhorst 2016), the Netherlands has also been the only country in the European Union where, since decades, the downside of the egg sector, the practice of killing day-old male chicks, is a recurrent subject of societal debate (Leenstra et al. 2011). In general, most Dutch people are unaware that all male chicks of layer breeds are killed directly after hatching (Leenstra et al. 2011). However, on hearing about it, most of them react disapprovingly. This societal resistance and strongly adverse reactions have led to political debate as well. As a result, different alternatives have been proposed, and the Dutch parliament has supported research into them a long time ago (Woelders et al. 2007). Technical and practical arguments show that some of the alternatives do not seem to be viable. For example sex ratio adjustment is possible by influencing the hen, e.g. by restricted feeding programs, but not very effective. It also induces welfare problems for the hens (Aslam et al. 2014). By studying the social acceptability of the main alternatives to killing day-old male chicks in the Netherlands, we aim to obtain relevant findings that can be helpful in the international assessment of these alternatives.

Based on technical and practical perspectives, two approaches can be defined as possible solutions for killing day-old chicks. The first approach aims at preventing the killing of very young animals by keeping the male chicks alive for a longer period of time. This can be achieved in two ways. One way is by rearing the males of layer breeds to produce meat. However, this is an inefficient way of producing chicken meat, and the meat is not comparable to broiler meat (Damme and Ristic 2003). The other way is to use dual-purpose breeds for the production of eggs. The meat is then, with respect to taste and structure, reasonably comparable to broiler meat. A disadvantage of reversing specialised egg production is that it is less efficient with regard to resource input and waste output (Leinonen et al. 2012), and as a consequence the products will be more expensive. Moreover, it is questioned 
whether the quality of life of the males is good (enough) when they are kept alive longer. The second approach aims at in ovo sex determination, in which the killing of very young animals is avoided by preventing the animals from being born. Different techniques can be distinguished, aiming at different points in the incubation period. In ovo sex determination is, however, not yet ready for practical use (e.g. Koenig et al. 2012). Even when a proof of principle in the laboratory has been given, machines for use in the hatcheries have to be developed that are fast, reliable, and cheap, and that not affect hatchability or the health and performance of the laying hens (Kaleta and Redmann 2008). The preferred method would be to determine sex before incubation, as embryonic development has then not yet started (Close et al. 1997; Weissmann et al. 2013). Techniques to determine sex in the second half of 39 the incubation period have already been developed, but have not been put into practice. In the case of sex determination during incubation, half of the eggs could be removed from the incubators during the incubation period, saving some energy and costs (the number of incubators cannot be reduced; only the hatchers can be reduced by half). The male eggs would be destroyed.

One of the potential techniques involves the use of genetic modification (GM) in the breeding lines of layer chickens (Schuppli and Weary 2010). This technique might facilitate sex determination before incubation. Other techniques aim at taking a sample from the hatching egg in order to find differences between male and female eggs, mostly based on hormone levels at the beginning of, or halfway through, the incubation period (Weissmann et al. 2013). The in ovo sex determination approach does not increase the resource use or waste output, and there is no change in the price or quality of the end products. However, this direction leads to new dilemmas, such as whether the killing of embryos is better or worse than killing day-old male chicks, or whether the techniques used to detect the sex of the eggs are acceptable, especially the GM technique (Lassen et al. 2006).

It is clear that both approaches solve the problem of killing day-old male chicks (either by keeping them alive or by preventing them from living), but they also raise a lot of new animal welfare related dilemmas. As a theoretical background to our online survey, we used an ethical framework (...) in which the killing of day-old male chicks and the two alternative approaches are analysed (see the ethical matrix in Table 1). Our ethical framework is based on the two main approaches in bioethics: a consequentialist approach (e.g. Singer 1993) and a deontological approach (e.g. Regan 1983). Beauchamp and Childress (1994) use these approaches to define four commonly used principles: non-maleficence, beneficence, autonomy, and justice.

Mepham (2000) developed these principles into an ethical matrix that combines consequentialist and deontological approaches on the horizontal axis, to structure the different ethical aspects for different stakeholders. The ethical principles are represented by the principles of wellbeing, autonomy, and justice. On the vertical axis, we distinguish four main stakeholders: society (most members of which are also consumers), the egg sector, day-old male chicks, and the environment [as is common when working with the ethical matrix, (Mepham 2000)].We used the ethical matrix to structure questions 2 and 10 of the online survey (see Table 2), and to identify the stakeholders' perspectives with regard to the arguments used. 
Table 1 Ethical arguments for the stakeholders on the issue of killing day-old chicks and its alternatives contained in the ethical matrix, based on (Mepham 2000)

\begin{tabular}{|c|c|c|c|}
\hline Respect for: & Wellbeing & Autonomy & Justice \\
\hline $\begin{array}{l}\text { Society } \\
\text { (consumers of } \\
\text { eggs) }\end{array}$ & $\begin{array}{l}\text { Acceptability } \\
\text { Food safety }\end{array}$ & $\begin{array}{l}\text { Consumer } \\
\text { choice }\end{array}$ & $\begin{array}{l}\text { Affordability } \\
\text { Availability }\end{array}$ \\
\hline Egg sector & $\begin{array}{l}\text { Maintain } \\
\text { profitability (good } \\
\text { income) } \\
\text { Adequate labor } \\
\text { conditions }\end{array}$ & $\begin{array}{l}\text { Freedom of } \\
\text { management }\end{array}$ & $\begin{array}{l}\text { Fair treatment in trade and law (level } \\
\text { playing field, international competition) }\end{array}$ \\
\hline Day-old chicks & Animal welfare & $\begin{array}{l}\text { Integrity } \\
\text { Naturalness }\end{array}$ & Intrinsic value \\
\hline Environment $^{\mathrm{a}}$ & $\begin{array}{l}\text { Protection of the } \\
\text { biota }\end{array}$ & $\begin{array}{c}\text { Maintenance of } \\
\text { biodiversity }\end{array}$ & Sustainability \\
\hline
\end{tabular}

${ }^{a}$ For this case, we focus only on the environmental impact with regard resource use and waste output as the other elements will be too extensive to discuss in this paper

In this article, the results of this survey are analysed. Key preferences of society regarding the two alternative approaches to solve the problem of killing day-old male chicks are identified (scientific contribution). Also, we will find out what approach in research and innovation should deserve more (political) support (societal contribution). In order to achieve this goal, our main research question is: 'What is the preferred way for dealing with day-old male chicks in the egg sector?' Two interrelated sub-questions are answered in this article: 'How do people in Dutch society perceive the killing of day-old male chicks in the egg sector?' and 'How are proposed alternative approaches valued by people in Dutch society?'

\section{Materials and Methods}

The survey included 10 main questions and two blocks of text (see Table 2) to provide the respondents some essential information.

A valorization panel, required by the funding agency (the Netherlands Organization for Scientific Research) in order to stimulate the valorization of scientific knowledge in practice, functioned as a consultative group for the content of the survey. This panel consisted of various stakeholders, namely: farmer representatives (i.e. people representing the breeding organizations, hatcheries, and breeding farms, and laying hen farmers), representatives of consumers, of retail, and of animal protection organizations. The final version of the survey was piloted on 10 people. Some adjustments were made before launching the survey on the internet.

The online survey was in Dutch and was held from 16 October 2015 to 1 December 2015 using the database of a Dutch survey company. The following criteria were used to select the respondents: 
Table 2 Questions used in the online survey, with the multiple choice options of the online survey indicated between brackets

1. Do you think it is acceptable to keep animals to produce food? [Yes, No, No opinion]

2. How important are the following motives for producing eggs? [5-point scale from very unimportant to very important] a. Environment; b. Availability of food; c. Affordability of food; d. Food safety; e. Animal health and welfare; f. Income of people in the egg sector

3. What is your opinion about killing day-old male chicks? a. No opinion; b. Good solution; c. No problem; d. Inevitable; e. Alternatives needed; f. Has to stop; g. Other

Text block 1. First alternative: to use cockerels for meat production Currently, the cockerels of layer breeds are killed when they are 1 day old. A solution could be to use these cockerels for the production of meat. There are roughly two ways to do this: to develop a less specialized chicken and feed the cockerels until they are about 10 weeks old or to feed the cockerels of the layer hen breeds until they are about 10 weeks old. Meat chickens (cockerels and hens) are slaughtered at the age of about 6 weeks. In the Netherlands, we eat mainly the breast meat of meat chicks. The cockerels of less specialized chickens grow more slowly, and their breast meat tastes different compared to meat chickens. If these cockerels are reared to 10 weeks, they will be sold as whole cockerels. The preparation method and taste of the breast meat will be different. Also, the hens of less specialized breeds lay $20 \%$ fewer eggs, and their eggs have a less equal brown colour. Taste and nutritional value are comparable. More time and feed are needed to grow cockerels from less specialized breeds, the environmental burden is higher, and the meat and/or eggs are more expensive

4. Do you think these two options are acceptable? [5-point scale: totally unacceptable to totally acceptable] a. Less specialized breed to produce eggs and b. To eat the cockerels and to slaughter the cockerels of layer hen breeds at the age of 10 weeks

5. How important are the following aspects in your answer to question 3? (5-point scale: very unimportant to very important) a. Price of the product; $b$. Age of cockerels when they are slaughtered; c. Quality of life when they live longer; d. Taste of the meat; e. Preparation of the meat; f. Colour of the eggs; g. Environmental burden

Text Block 2. Alternative two: sexing in the egg. There are different ways of sexing chickens at different times in the breeding process. It takes 21 days for a chick to hatch. There are three options available: 1 . Genetic modification using a fluorescent gene of a jelly fish. This gene is transferred only to the cockerels. By shining a special light on the eggs before they go into the incubator, one can distinguish the cockerels from the hens. The eggs containing the cockerels will be destroyed. 2 . From day 9 onwards: take a sample from an egg and analyse it. The eggs containing the cockerels will be destroyed. 3. From day 11 onwards: use a special light to determine the eggs with the cockerels. This can be done only with brown chicken breeds. The eggs containing the cockerels will be destroyed

6. What is your opinion about these three alternative options? (5-point scale: totally unacceptable to totally acceptable) a. Genetic modification; b. Take a sample from the egg; c. Shine a special light on the eggs

Genetic modification is a modern kind of biotechnology. The aim is to transfer a desirable trait from species A to species B by inserting genetic material from species A into species B. Which claims about the use of genetic modification apply? (It is possible to choose more than one option)

7. Genetic modification is acceptable; Acceptable, but not in my food; Acceptable, but not in plants; Acceptable but not in animals; Acceptable but not in all animals; Not acceptable

8. How important are the following motives for the genetic modification of animals? (5-point scale from very unimportant to very important) a. Human control over animals; b. Possible public health risks; c. Possible animal health risks; d. Possible nature and environmental risks; e. Possible negative effects on animal welfare; f. Affecting animal naturalness

9. Your preference with regard to dealing with day-old male chicks? a. Keep current situation; b. Dual purpose breed; c. Rear layer males; d. Genetic modification; e. Sampling eggs; f. Spectroscopy on eggs 
Table 2 continued

10. How important are the following motives for how to deal with day-old male chicks? (5-point scale from very unimportant to very important) a. Environment; b. Availability of food; c. Affordability of food; d. Food safety; e. Animal health and welfare; f. Income of people in the egg sector

Four questions about personal background 1. Sex; 2. Year of birth; 3. Province; 4. Level of education

1. We want to analyse the values of the Dutch society, so we will remove all nonDutch, for example Belgian, respondents.

2. The intention is to obtain a sample that would be representative of the Dutch population (more than 1000 respondents). The invitation to fill out the survey is aimed at this, using sex, age, level of education, and area of residence as control variables.

3. We only select respondents who answered all questions because most of the ten questions are connected to other questions and together they cover all the issues we are interested in. So, we will remove people who skipped a question.

4. The survey starts with the question 'Do you think it is acceptable to keep animals to produce food?' If people answered that they found this unacceptable or that they did not know, they could choose to stop filling out the survey.

The survey continues by asking respondents' opinion on the importance of different motives, from our ethical framework, for producing eggs, and their opinion about killing day-old male chicks. The next part of the survey is about 'dual use of chickens', the first alternative approach. First an information block is provided about the options of this approach; and then questions are asked about how acceptable people find the options in this alternative approach and to what extent certain motives form our ethical framework, play a role in their judgement. The same procedure is followed for the three options under the heading in ovo sex determination', the second alternative approach (see Table 2).

The survey attracted 2219 respondents; however, not all of these were useful for further analysis. The following criteria were used to remove respondents from the dataset. People who skipped questions were removed (941 respondents), as were respondents who were not Dutch (77 respondents). In addition, we removed all respondents (179) who filled in a complete questionnaire in December (we received the data on December 15th, 2 weeks after the planned end of the survey). This resulted in a dataset of 1022 respondents.

The data were analysed using Statistical Package for the Social Sciences (SPSS, version 22). We started the analysis with descriptive statistics about the most important questions. In order to ascertain whether any differences were statistically significant appropriate tests were executed. $\mathrm{X}^{2}$-tests were performed on the most important questions to establish effects due to socio-demographic characteristics (opinion about current approach, the alternative approaches, and preference for dealing with day-old male chicks). In order to test whether valuations of arguments were significant, the Friedman-test was done, and if needed followed by a Wilcoxon-test. 


\section{Results}

\section{Socio-Demographic Characteristics}

As shown in Table 3, the data are not completely representative of the Dutch population, mainly because the group of more highly educated people and the 50-69 age group are overrepresented. The more highly educated people and older age groups are more aware of the current approach of killing day-male old chicks $\left(\mathrm{X}^{2}=11.28, p<0.05\right.$ and $\left.\mathrm{X}^{2}=62.26, p<0.05\right)$. However, they have fewer problems with the practice than people who do not know about it $\left(X^{2}=45.22\right.$, $p<0.05)$. Preference on how to deal with these chicks is affected by awareness as well $\left(\mathrm{X}^{2}=11.64, p<0.05\right)$,). No option reached a majority. The area of residence (province) does not affect awareness $\left(\mathrm{X}^{2}=15.62, p>0.05\right)$, respondents' opinion

Table 3 Respondent characteristics: socio-demographic characteristics compared to Dutch population

\begin{tabular}{|c|c|c|c|}
\hline & Sample (N) & Sample $(\%)$ & Dutch population $^{\mathrm{a}}(\%)$ \\
\hline \multicolumn{4}{|l|}{ Gender } \\
\hline Male & 489 & 47.8 & 49.3 \\
\hline Female & 533 & 52.2 & 50.7 \\
\hline \multicolumn{4}{|l|}{ Education } \\
\hline Low & 118 & 12 & 31 \\
\hline Middle & 367 & 36 & 41 \\
\hline High & 537 & 53 & 28 \\
\hline \multicolumn{4}{|l|}{ Age } \\
\hline$<30$ & 201 & 20 & 27 \\
\hline $30-49$ & 336 & 33 & 30 \\
\hline $50-69$ & 425 & 42 & 29 \\
\hline$>69$ & 60 & 6 & 13 \\
\hline \multicolumn{4}{|l|}{ Province } \\
\hline Groningen & 66 & 7 & 3 \\
\hline Friesland & 50 & 5 & 4 \\
\hline Drenthe & 37 & 4 & 3 \\
\hline Overijssel & 86 & 8 & 5 \\
\hline Gelderland & 131 & 13 & 11 \\
\hline Flevoland & 24 & 2 & 3 \\
\hline Utrecht & 90 & 9 & 7 \\
\hline Noord-Holland & 138 & 14 & 18 \\
\hline Zuid-Holland & 158 & 16 & 23 \\
\hline Zeeland & 13 & 1 & 2 \\
\hline Noord-Brabant & 153 & 15 & 14 \\
\hline Limburg & 75 & 7 & 7 \\
\hline
\end{tabular}

${ }^{a}$ CBS Statline, accessed January 2015 
about the current approach $\left(\mathrm{X}^{2}=52.52, p>0.05\right)$, or their preference for an alternative approach $\left(\mathrm{X}^{2}=68.20, p>0.05\right)$. People who grew up in the countryside had fewer problems with the killing of day-old male chicks, whereas urban people more often wanted a search for alternatives $\left(\mathrm{X}^{2}=47.50, p<0.05\right)$. People who grew up in the countryside are also more aware of the practice $\left(\mathrm{X}^{2}=20.84, p<0.05\right)$. There are significant differences between men and women. Women are less aware than men $\left(44\right.$ vs. $\left.56 \%, \mathrm{X}^{2}=15.68, p<0.05\right)$ and have a stronger tendency to ask for alternative approaches or for the practice to stop, whereas more men think that the killing of day-old male chicks is a good solution or do not have problems with it $\left(\mathrm{X}^{2}=36.79, p>0.05\right)$. Women differ in their preference with respect to the dual use alternative; they prefer a less specialized breed over rearing cockerels (as is the case for the unaware group in which there are more women); however, there is no one preferred solution.

\section{Killing Day-Old Chicks}

The survey shows that $55 \%$ of respondents are aware of the killing of day-old male chicks. In Fig. 1, we find that about $30 \%$ of respondents think that it is a good practice or do not have problems with it. Almost half of the people disagree with it and would rather search for alternative approaches or indicate that it should stop immediately.

\section{Alternatives}

Table 4 shows how the respondents value the acceptability of the different alternatives. There is no one alternative that has a much higher percentage for acceptability. The two 'dual use' options score a relatively low percentage for being unacceptable, but score a high percentage for people being neutral about them.

Fig. 1 Opinion of citizens about killing day-old chicks

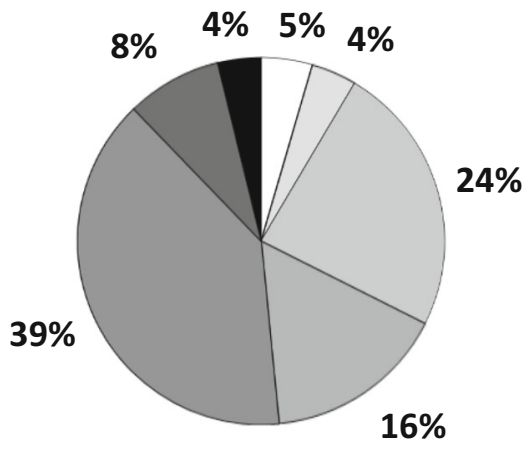

$\square$ No opinion $\square$ Good solution $\quad \square$ No problem
$\square$ Inevitabe $\square$ Alternatives needed $\square$ Has to stop
$\square$ Other


Table 4 Respondents' opinions about alternative approaches $(\mathrm{N}=1022)$

\begin{tabular}{|c|c|c|c|}
\hline \multirow[t]{2}{*}{ Alternative approaches } & \multicolumn{3}{|c|}{ Percentage of respondents $(\%)$} \\
\hline & Unacceptable & Neutral & Acceptable \\
\hline \multicolumn{4}{|l|}{ 1. Dual use } \\
\hline Dual-purpose breed & 20.4 & 38.4 & 41.3 \\
\hline Rearing layer males & 20.3 & 38.5 & 41.3 \\
\hline \multicolumn{4}{|l|}{ 2. In ovo sex determination } \\
\hline $\begin{array}{l}\text { GM to facilitate non-invasive sex determination before } \\
\text { incubation }\end{array}$ & 30.3 & 26.5 & 43.2 \\
\hline $\begin{array}{l}\text { Invasive sex determination at day } 9 \text { of incubation period by } \\
\text { taking sample from the eggs }\end{array}$ & 33.5 & 29.1 & 37.5 \\
\hline $\begin{array}{l}\text { Non-invasive sex determination at day } 11 \text { of incubation period } \\
\text { using spectroscopy }\end{array}$ & 28.2 & 29.5 & 42.3 \\
\hline
\end{tabular}

From the options for 'in ovo sex determination', 'sampling on day 9' has the lowest score for acceptability. Friedman's test and the post hoc Wilcoxon-test confirm that only the sampling of hatching eggs scores significantly lower on acceptability $\left(\mathrm{X}^{2}=29.51, p<0.05, \mathrm{Z}=-3.53\right.$ and $\left.\mathrm{Z}=-5.57, p=0.00\right)$.

In relation to preference for how to deal with day-old male chicks (Fig. 2), no one option has a preference of more of $50 \%$, but there is a big difference of $21.6 \%$ between the lowest option 'sampling eggs' and the highest option 'keep the current situation.'

\section{Importance of Arguments from the Ethical Framework}

\section{Society}

The results of the question 'What do you think about the fact that day-old male chicks are killed?' (Fig. 1) already show that there is wide divergence between the different options in Dutch society. For the two alternative approaches the acceptability of the different options has been asked (Table 4) which showed no consensus but again a wide distribution between the options. The option of taking a sample at day 9 was the least preferred.

The importance of food safety as an issue of wellbeing for society was asked in different questions. The data show that this argument is most important to people when they are thinking about the importance of producing protein-rich food, like chicken meat and eggs (Tables 5 and 6; but also when they are thinking about GM, food safety has the highest score (Friedman's test $\mathrm{X}^{2}=693.29, p<0.05$ ). Post hoc analysis with Wilcoxon signed-rank tests was conducted with a Bonferroni correction applied, resulting in a significance level set at $p<0.0033$.

With respect to GM, the arguments relating to risks score higher than the argument relating to the principles of human control over animals and naturalness (Table 7). Availability is more important than affordability (Tables 5, 6). 


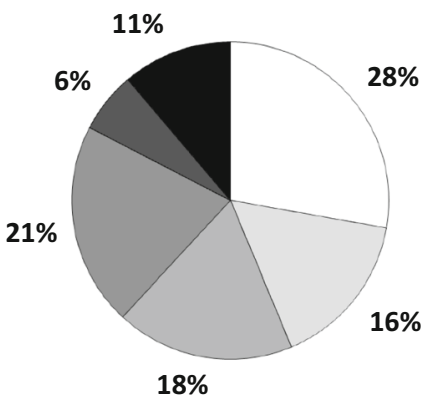
$\square$ Keep current situation $\square$ Dual-purpose breed
Rear layer males
$\square$ Genetic Modification $\square$ Sampling effs
Spectroscopy on eggs

Fig. 2 Preference of citizens about killing day-old chicks

Table 5 Values and ranking of the different arguments in question 2: importance of the arguments for the production of protein-rich food, like chicken meat and eggs? (scale 1-5)

\begin{tabular}{lc}
\hline Argument & Mean rank \\
\hline Food safety & 5.91 \\
Respect for animals & 5.28 \\
Animal health and welfare & 5.16 \\
Availability & 4.37 \\
Affordability & 4.04 \\
Environment (resource use and waste output) & 3.70 \\
Good income for people in the egg sector & 3.51
\end{tabular}

Friedman's test $\mathrm{X}^{2}=1284.49, \mathrm{df}=1, p<0.051$, Post hoc analysis with Wilcoxon signed-rank tests was conducted with a Bonferroni correction applied, resulting in a significance level set at $p<0.0018$

\section{Egg Sector}

For all the arguments concerning the egg sector, the scores are relatively low (Tables 5, 6). The good income of the Dutch egg sector is the least important argument compared to the other arguments about how to deal with day-old male chicks (Table 6). Also the value of the adequate labour circumstances of 177 the farmers are relatively low (Table 5).

\section{Status of Day-Old Chicks}

The scores for arguments relating to the day-old male chicks are relatively high, only 'food safety' scores higher than 'animal health and welfare' and 'respect for animals' (Tables 5, 6). The same applies to the questions about GM (Table 7), and is also visible in other questions, e.g. the question about arguments relating to 'the 
Table 6 Values and ranking of the arguments when considering how to deal with day-old male chicks in question 10: How important are the following motives for how to deal with day-old male chicks? (scale $1-5)$

\begin{tabular}{lc}
\hline Argument & Mean rank \\
\hline Food safety & 4.99 \\
Animal health and welfare & 4.71 \\
Respect for animals & 4.69 \\
Availability & 3.71 \\
Environment (resource use and waste output) & 3.60 \\
Affordability & 3.38 \\
Good income for people in the egg sector & 2.93 \\
\hline
\end{tabular}

Friedman's test $\mathrm{X}^{2}=1205.29, \mathrm{df}=1, p<0.051$, Post hoc analysis with Wilcoxon signed-rank tests was conducted with a Bonferroni correction applied, resulting in a significance level set at $p<0.0023$

Table 7 Values and ranking of the different arguments in question 8: How important are the following motives for the genetic modification of animals? (scale 1-5)

\begin{tabular}{lc}
\hline Argument & Mean rank \\
\hline Risks public health & 4.08 \\
Risks animal health & 3.76 \\
Risks environment & 3.64 \\
Risks animal welfare & 3.63 \\
Affecting naturalness of the animal & 3.27 \\
Human control over animals & 2.63
\end{tabular}

Friedman's test $\mathrm{X}^{2}=693.29 \mathrm{df}=1, p<0.053$, Post hoc analysis with Wilcoxon signed-rank tests was conducted with a Bonferroni correction applied, resulting in a significance level set at $p<0.0033$

dual use of chickens.' The results of this question show that the animals' quality of life is valued highest.

\section{Environment}

The questions relating to the environment concern resource use and waste output (see Fig. 1). In Tables 5 and 6 it is clear that 'environment' is considered less important than 'animal health and welfare'; but the scores of specific questions, such as the question about dual use of chickens, show that 'environment' is in the middle with regard to importance. In reply to a question specifically about whether a higher impact on the environment is acceptable for the alternative direction of dual use, $40 \%$ find this unacceptable, $33 \%$ acceptable, and $27 \%$ do not know what to think. 


\section{Discussion and Conclusion}

\section{Limitations of Data Collection and Interpretation}

It doubtful whether all the respondents completely understood the animal welfarerelated issues at stake. The respondents try to link some of the information to subjects that they know more about or have heard about. The value of providing information in a survey is debatable and was a point of discussion in the valorization panel as well. The respondents need too much knowledge about the subject in order to be able to decide whether they prefer eggs with or without killing day-old male chicks. This is illustrated by previous studies as well, which showed that only about half of respondents knew about the killing (Leenstra et al. 2011). Considering the reliability of the answers, also in combination with the complexity of the subject and the number of drop-outs, one could argue that the survey should give less information. However, with this amount of information provided, respondents already indicated that they did not to have enough information to form an opinion.

\section{Actuality of This Subject}

What is the influence of media on awareness? In a 2007 survey (Leenstra et al. 2011), 42\% of respondents were aware, whereas in our 2014 survey $55 \%$ of respondents were aware. It seems that media attention influences awareness because, at the end of 2013, a lot of media-attention focused on GM as the solution for the problem of killing day-old male chicks. The Dutch State Secretary of Agriculture wanted to give permission to execute an experiment as proof-ofprinciple for this option. We assume that these numbers show that more people are aware of this practice when there has been media attention in the recent past.

\section{Best Alternative?}

The answer to our main research question, 'What is the preferred way of dealing with day-old male chicks in the egg sector?', is that there is no one alternative approach that will be fully accepted by society or accepted by more than half of society. However, the survey does give insight into what people think is important for their choice: food safety and a good treatment of animals are most important to people. Irrespective of the alternative, these values should be safeguarded and communicated clearly.

Although $20.7 \%$ of respondents chose for the GM option-relatively high compared to 'sampling the eggs' $(6.2 \%)$ and 'spectroscopy' $(11.2 \%)$ - the results nevertheless score high values for concerns about risks of the GM option (Table 6). Also, the opinions about this option are more extreme than for the other options (see also Macnaghten 2004). The results of the restricted question about choosing between the options of the GM technique of killing day-old male chicks illustrate strong emotions: various people commented it was not sound to ask this in a survey. However, this scenario is rather common (Frewer et al. 2013). Furthermore, people 
have their reservations when arguing about this. There is always an 'unless' or 'if'. When given a restricted choice, more people choose killing day-old male chicks (59\%) than using GM (where no chicks or embryos are killed). The relatively high concern about GM is also shown by the high scores for the different arguments about GM.

In 2014, this lead to the refusal of the Dutch parliament to start the proof-ofprinciple research on Wageningen University and Research's theoretical GM option. The State Secretary decided to financially support a new start-up company in Leiden, which samples hatching eggs. However, it is interesting to see that our results show that this alternative receives the lowest preference $(6.2 \%)$, whereas the GM option received a preference of $20.7 \%$. Although the aspect of determining sex before incubation could make this technique interesting, we think that the sampling of hatching eggs or destroying hatching eggs with embryos could be problematic as well, because the destroyed eggs cannot be used.

Our first sub-question, 'How do people in Dutch society perceive the killing of day-old male chicks in the egg sector?,' is answered by the fact that fewer than $30 \%$ of respondents support the current approach. More than $23670 \%$ are in favour of an alternative approach, but there is no consensus about the two main alternative approaches. The scores for the Dutch poultry sector are relatively low compared to arguments such as food safety and availability and animal health and welfare. Our results show that all arguments from the ethical matrix are important, but that arguments relating to people's health and to the health and welfare of animals are relatively more important. The answer to our second sub-question, 'How are proposed alternative approaches valued by people in Dutch society?' is that this study shows that neither of the alternative approach receives support from a majority of society. In the process of searching for the optimal way of dealing with day-old male chicks, these arguments/values should be included and communicated very clearly.

\section{How to Deal with Cockerels in the egg Sector Responsibly?}

The data from our survey show that there is no consensus about how to deal with cockerels in the egg sector. The arguments that are most important for people relate to themselves and to the animals. The most important arguments are food safety, health, and the welfare of and respect for animals. Even if the egg sector tried to incorporate the steps of responsible innovation, namely, anticipate intended and potentially unintended future impacts of innovations; reflect on the purposes, motivation, and potential impact of their innovations; deliberate with multiple stakeholders; and respond to societal needs through participatory and anticipatory governance (Owen et al. 2013), there is no alternative approach that would be acceptable to a majority of the Dutch public. We have described this situation as a 'moral lock-in'. This is caused by the fact that the emergence of this practise is rooted in the development of a highly efficient production system, driven by values other than the values that are at stake for different stakeholders (in this time period in North-western Europe) (Blok and Lemmens 2015). However, the sector is not unwilling, but cannot make real changes. As long as the current approach seems to 
be the least of multiple evils, it might be better not to change how we deal with dayold male chicks as long as there is not an alternative that is accepted more broadly. Advances in the abovementioned techniques or maybe more extreme alternatives (e.g. eat plant-based proteins) are needed to unlock the moral problem of killing day-old male chicks.

Funding The work in this article was funded by NWO (Netherlands Organization for Scientific Research) (Grant Number 263 313-99-015).

Open Access This article is distributed under the terms of the Creative Commons Attribution 4.0 International License (http://creativecommons.org/licenses/by/4.0/), which permits unrestricted use, distribution, and reproduction in any medium, provided you give appropriate credit to the original author(s) and the source, provide a link to the Creative Commons license, and indicate if changes were made.

\section{References}

Aslam, M. A., Groothuis, T. G. G., Smits, M. A., \& Woelders, H. (2014). Effect of corticosterone and hen body mass on primary sex ratio in laying hen (Gallus gallus), using unincubated eggs. Biology of Reproduction, 90, 4-11.

Beauchamp, T. L., \& Childress, J. F. (1994). Principles of biomedical ethics. New York: Oxford University Press.

Blok, V., \& Lemmens, P. (2015). Critical reflections on the concept of responsible innovation. In B. J. Koops, J. Van den Hooven, H. A. Romijn, T. E. Swierstra, \& I. Oosterlaken (Eds.), Responsible innovation: Issues in conceptualization, governance and implementation. Dordrecht: Springer.

Close, B., Banister, K., Baumans, V., Bernoth, E. M., Bromage, N., Bunyan, J., et al. (1997). Recommendations for euthanasia of experimental animals-part 2. Laboratory Animals, 31, 1-32.

Damme, K., \& Ristic, M. (2003). Fattening performance, meat yield and economic aspects of meat and layer type hybrids. Worlds Poultry Science Journal, 59, 50-53.

Frewer, L. J., Kleter, G. A., Brennan, M., Coles, D., Fischer, A. R. H., Houdebine, L. M., et al. (2013). Genetically modified animals from life-science, socio-economic and ethical perspectives: Examining issues in an EU policy context. New Biotechnology, 30, 447-460.

Kaleta, E. F., \& Redmann, T. (2008). Approaches to determine the sex prior to and after incubation of chicken eggs and of day-old chicks. World's Poultry Science Journal, 64, 391-399.

Koenig, M., Hahn, G., Damme, K., \& Schmutz, M. (2012). Utilization of laying-type cockerels as "coquelets": Influence of genotype and diet characteristics on growth performance and carcass composition. Archiv Fur Geflugelkunde, 76, 197-202.

Lassen, J., Gjerris, M., \& Sandoe, P. (2006). After Dolly—ethical limits to the use of biotechnology on farm animals. Theriogenology, 65, 992-1004.

Leenstra, F., Munnichs, G., Beekman, V., van den Heuvel-Vromans, E., Aramyan, L., \& Woelders, H. (2011). Killing day-old chicks? Public opinion regarding potential alternatives. Animal Welfare, 20, $37-45$.

Leinonen, I., Williams, A. G., Wiseman, J., Guy, J., \& Kyriazakis, I. (2012). Predicting the environmental impacts of chicken systems in the United Kingdom through a life cycle assessment: Broiler production systems. Poultry Science, 91, 8-25.

Macnaghten, P. (2004). Animals in their nature: A case study on public attitudes to animals, genetic modification and 'nature'. Sociology, 38, 533-551.

Mepham, B. (2000). A framework for the ethical analysis of novel foods: The ethical matrix. Journal of Agricultural and Environmental Ethics, 12, 165-176.

Mulder, N-D. (2017). Outlook for the Global and the EU industry. www.lf.dk/ /media/lf/296 for...og.../ 1-nan-dirk mulder.pdf.

Owen, R., Stilgoe, J., Macnaghten, P., Gorman, M., Fisher, E., \& Guston, D. (2013). A framework for responsible innovation. In R. Owen, J. Bessant, \& M. Heintz (Eds.), Responsible innovation. New York: Wiley.

Regan, T. (1983). The case for animal rights. Berkeley: University of California Press. 
Los Angeles Reporter Link. (2017). www.reportlinker.com/egg/report.

Schuppli, C. A., \& Weary, D. M. (2010). Attitudes towards the use of genetically modified animals in research. Public Understanding of Science, 19, 686-697.

Singer, P. (1993). Practical ethics. New York: Cambridge University Press.

Weissmann, A., Reitemeier, S., Hahn, A., Gottschalk, J., \& Einspanier, A. (2013). Sexing domestic chicken before hatch: A new method for in ovo gender identification. Theriogenology, 80, 1-7.

Windhorst, H.-W. (2016). The Netherlands-the leading country in European egg and poultry meat exports, ZooTechnica Intgernational, http://zootecnicainternational.com/focus-on/netherlandsleading-country-europeanegg-poultry-meat-exports.

Woelders, H., Brom, F. W. A., \& Hopster, H. (2007). Alternatieven voor doding eendagskuikenstechnologische perspectieven en ethische consequenties. Wageningen: Animal Sciences Group, Wageningen Universiteit \& Research. 